\title{
EL TRANSPORTE A LA DEMANDA COMO SISTEMA DE MOVILIDAD ALTERNATIVO EN ÁREAS RURALES DE BAJA DENSIDAD DEMOGRÁFICA: EL CASO DE CASTILLA Y LEÓN
}

\author{
José Ma Delgado Urrecho \\ Luis Carlos Martínez Fernández \\ Departamento de Geografía. Universidad de Valladolid \\ jose@fyl.uva.es, luiscar@fyl.uva.es
}

\section{RESUMEN}

El objetivo de este artículo es analizar cómo la despoblación del medio rural y la escasez de servicios, concentrados en las localidades de mayor entidad demográfica, han generado un aumento de la necesidad de desplazamientos a la par que el escaso número de usuarios no permite mantener las líneas de transporte convencionales. Ante esta problemática la propuesta por la administración pública de soluciones alternativas se plasmó en Castilla y León en el transporte a la demanda, una opción imaginativa que ha demostrado su viabilidad satisfaciendo en gran medida la demanda existente.

Palabras clave: Poblamiento, Castilla y León, rural, transporte a la demanda.

\section{ABSTRACT}

The aim of this article is to analyse how the depopulation in the rural areas and the scarcity of services, which are concentrated in the villages with higher demographic entity, have caused an increase of the necessity of displacements as well as the small amount of users does not allow to maintain the conventional transport lines. In view of these problems,

Fecha de recepción: diciembre 2014.

Fecha de aceptación: julio 2015. 
the proposal of alternative solutions by the public administration was reflected in the ondemand- transport of Castilla and León, an imaginative option that has shown its viability, satisfying greatly the present demand.

Keywords: Settlement, Castilla y León (Spain), rural, transport on demand.

\section{INTRODUCCIÓN}

El desplazamiento interurbano es, sin duda, uno de los servicios cuya demanda ha experimentado un mayor crecimiento en las últimas décadas, consecuencia tanto de la reordenación en la distribución de las actividades económicas como de los cambios en los modelos de poblamiento a todas las escalas y la aparición de nuevos hábitos de consumo y empleo del tiempo libre. La expansión superficial de las ciudades, con franjas periurbanas alcanzando cada día un mayor número de localidades, coincide cronológicamente con la concentración espacial de equipamientos y dotaciones en los centros de servicios del mundo rural, diversificándose los motivos y aumentando el número de desplazamientos. La despoblación de este último ámbito territorial en el interior peninsular ha ido restando rentabilidad a los negocios particulares en un cada día mayor número de núcleos con población decreciente, obligando a la modificación de los sistemas de prestación de servicios por parte de las diferentes administraciones públicas; unos servicios que afectan, en diferentes aspectos, a parte cuando no a la totalidad de los residentes (educación, sanidad, dependencia, administración). La utilización del automóvil particular como medio de desplazamiento es generalizada, pero no sólo no resuelve todas las necesidades dado el creciente número de habitantes incapaces de recurrir al mismo debido al intenso envejecimiento demográfico, sino que ocasiona nuevos problemas tanto de accesibilidad a las ciudades (congestión del tráfico, inversiones en viales, construcción de aparcamientos o contaminación, entre otros) como a los centros rurales (mantenimiento de una extensa red de carreteras, incremento de las distancias, accidentabilidad, etc.).

Ante esta situación, el transporte colectivo y su potenciación por parte de esas administraciones públicas es un requisito indispensable para satisfacer la demanda, si bien ha de realizarse una puesta en común con el sector privado para contribuir al ahorro de costes y amortizar la inversión económica y socialmente, aumentando la eficiencia y optimizando las subvenciones (Holmgren, 2012). La problemática es común a muchas regiones de la Unión Europea y ha supuesto el empeoramiento de la calidad de vida e impulsado el éxodo hacia las localidades de mayor tamaño en un proceso retroalimentado que potencia la despoblación de amplios territorios (Schwanen et al., 2013). La desigualdad en el grado de accesibilidad introduce un elemento de exclusión social en el ámbito rural y por tanto, aun existiendo limitaciones para su eliminación, constituye un objetivo social el tratar de minimizarlas (Farrington and Farrington, 2005). Para ello se desarrollaron sistemas alternativos de movilidad, como el taxi colectivo, el uso compartido del automóvil -carpooling- y el préstamo de vehículos - car sharing-, si bien no están al alcance de toda la población por motivos económicos o por la elevada edad de los posibles usuarios. Para hacer frente a estas necesidades, crecientes por el rápido envejecimiento demográfico, en la década de los años ochenta del pasado siglo surgen sistemas conocidos como Demand Responsive Transport en varios países europeos 
que ofrecen diferentes opciones, ya se trate de establecer rutas, paradas y horarios fijos o variables o de utilizar vehículos adecuados a la demanda existente en cada caso (Oña, 2010)ํ․ A comienzos del siglo XXI el proyecto ARTS (Actions on the integration of Rural Transport Services), financiado por el $5^{\circ}$ Programa Marco de Investigación y Desarrollo Tecnológico de la Dirección General de la Comisión Europea de Movilidad y Transportes entre septiembre de 2002 y 2004, tuvo como objetivo la prueba de diferentes sistemas para la mejora del transporte rural en comarcas de Austria, España, Finlandia, Grecia, Hungría, Irlanda, Reino Unido y Suecia, incluyendo entre sus experiencias diferentes fórmulas de transporte a la demanda. En España la intervención se realizó en Galicia e incluyó los municipios orensanos de Viana do Bolo, Vilariño de Conso, O Bolo y A Veiga. Su objetivo fue la integración del transporte escolar y el de pasajeros en general, permitiendo que los adultos ocupasen las plazas vacantes, por lo que proporcionaba la oportunidad a los usuarios de desplazarse a los núcleos de servicios donde se localizaban los centros escolares. Se mejoraba así la reducida oferta de los servicios de transporte convencionales y a la par incrementaba los beneficios de los operadores (ARTS, 2003: 94-110). Este y otros tipos de actuaciones similares de carácter puntual fueron comunes a varias CC.AA. españolas a comienzos de siglo, en especial en el sector noroccidental de la Península, caracterizado por el mayor envejecimiento y dispersión de la población rural'2.

El objetivo de este trabajo reside en analizar esta problemática en Castilla y León, que debido a su extensión superficial y al tipo de poblamiento se sitúa entre las comunidades autónomas con mayores necesidades en este sentido. Para hacerlo se ha partido de investigaciones dirigidas por los autores en el marco del convenio de colaboración existente entre el Consejo Económico y Social de Castilla y León y la Universidad de Valladolid, combinando y confrontando el trabajo de campo con las estadísticas disponibles y estudiando a modo de ejemplo los servicios con carencias más obvias. Junto a la utilización de varias fuentes estadísticas y documentales a escala regional y municipal (Padrón Municipal de Habitantes, Datos Económicos y Sociales de las Unidades Territoriales de España, FUNDETEC y en especial, informes elaborados por la Consejería de Fomento y Medio Ambiente de la Junta de Castilla y León), la realización de encuestas a consumidores, usuarios y Centros de Acción Social en el medio rural, así como de entrevistas a responsables municipales, han resultado indispensables para recabar la información necesaria, que abarca desde comienzos del nuevo siglo hasta 2014. Una vez expuesta la problemática se analiza la puesta en marcha y el funcionamiento del transporte a la demanda a escala regional y, con mayor detenimiento, en el caso de la provincia de Segovia, abordado en el Diagnóstico Territorial elaborado por los autores para el Plan Estratégico Provincial. Los resultados permiten concluir que esta modalidad de transporte cumple los requisitos impuestos por el modelo de poblamiento y según los propios usuarios, satisface en gran medida sus actuales necesidades, siendo una opción adecuada para otros territorios con similares características.

1 Los países donde se han puesto en marcha estas experiencias son Alemania, Austria, Bélgica, Dinamarca, Finlandia, Francia, Holanda, Irlanda, Italia, Noruega, Reino Unido y Suecia.

2 En Asturias el Programa Rompiendo Distancias, gracias a un convenio entre el Principado, la Obra Social Cajastur, Mancomunidad de la Sidra, Mancomunidad Oriental de Cangas de Onís, Onís, Amieva y Ponga, junto al Ayuntamiento de Taramundi, inició en abril de 2001 un servicio de microbús en 37 localidades con ocho rutas mensuales (Suárez, 2004). 


\section{POBLAMIENTO, SERVICIOS Y PROBLEMÁTICA DEL TRANSPORTE DE VIAJEROS EN EL MEDIO RURAL}

\section{II.1. El modelo de poblamiento castellano y leonés}

Castilla y León se caracteriza por su amplia superficie $\left(94.226 \mathrm{~km}^{2}\right.$, el 18,6\% de la española) y escasa población (2.494.790 habitantes en 2014, el 5,3\%) por lo que su densidad es extremadamente baja, la segunda menor de todas las CC.AA. tras Castilla-La Mancha. El promedio de 26,5 hab/ $\mathrm{km}^{2}$ en 2014 enmascara además los fuertes contrastes entre unos espacios urbanos y periurbanos donde se concentra el 59,0\% de sus residentes en tan solo 42 municipios, con valores medios de $454 \mathrm{hab} / \mathrm{km}^{2}$, frente a un medio rural fragmentado en 2.206 municipios donde ese cociente desciende a $11,3 \mathrm{hab} / \mathrm{km}^{2}$. Pero también en este ámbito los desequilibrios territoriales son sumamente elevados, pues solo 89 municipios superan los dos mil residentes aunque en ellos habita un $72 \%$ de la población rural. La mayoría de los restantes (1.986) no alcanza el millar y su tamaño medio es de 247 habitantes, correspondiéndoles una población total de 462.551 personas y una densidad de $6,5 \mathrm{hab} / \mathrm{km}^{2}$. Y pese a lo significativo de estos datos, se trata de unidades administrativas, no de localidades, puesto que el número de ellas asciende a 6.151, de las cuales 5.586 poseen menos de mil habitantes y 3.704 no llegan al centenar. Baste pues este conjunto de cifras para dar una idea, al menos aproximada, de las dificultades inherentes al modelo de poblamiento regional, afectado por el alto grado de dispersión de su población y, en consecuencia, de la importancia de contar con una red de centros de servicios capaz de atender las necesidades dotacionales de toda índole (Martínez y Delgado, 2013). Una red cuya pervivencia se encuentra amenazada por la caída de la demanda debido a la creciente despoblación rural, dado que la población residente en las áreas de influencia de los centros comarcales mantiene una constante tendencia a la baja, apenas amortiguada en la primera década del presente siglo por la inmigración extranjera. Solamente los centros cercanos a las ciudades, los localizados a lo largo de los principales ejes de transporte y los núcleos turísticos escapan a esa situación (Figura 1). Por el contrario, en las áreas de menor densidad las pérdidas demográficas son constantes y tanto el número de centros como de actividades económicas en ellos existentes tiende a reducirse (Bachiller y Molina, 2014). En definitiva, la despoblación es a la par causa y consecuencia del declive dotacional y de la disminución de la accesibilidad a servicios de interés general, un problema común a los espacios rurales europeos de escasa densidad de población (Noguera y Ferrandis, 2014: 396).

Ante este modelo de poblamiento, el transporte de viajeros constituye en el medio rural un servicio indispensable cuyas necesidades reales distan mucho de encontrarse cubiertas por las líneas regulares. Los desplazamientos hacia centros comarcales y ciudades son consustanciales a la vida en las pequeñas localidades, dependiendo buena parte del abastecimiento de sus habitantes de la utilización de vehículos propios o del transporte público. El análisis de esta situación previa al funcionamiento del transporte a la demanda se ha efectuado considerando dos aspectos esenciales: en primer lugar, una aproximación a la disponibilidad de servicios y en caso de ausencia o inadecuación de los mismos a la 
obligatoriedad de realizar desplazamientos para cubrir ese déficit; en segundo lugar, a la oferta de servicios públicos para el transporte de pasajeros y, en general, a la capacidad de movilidad espacial de la población rural.

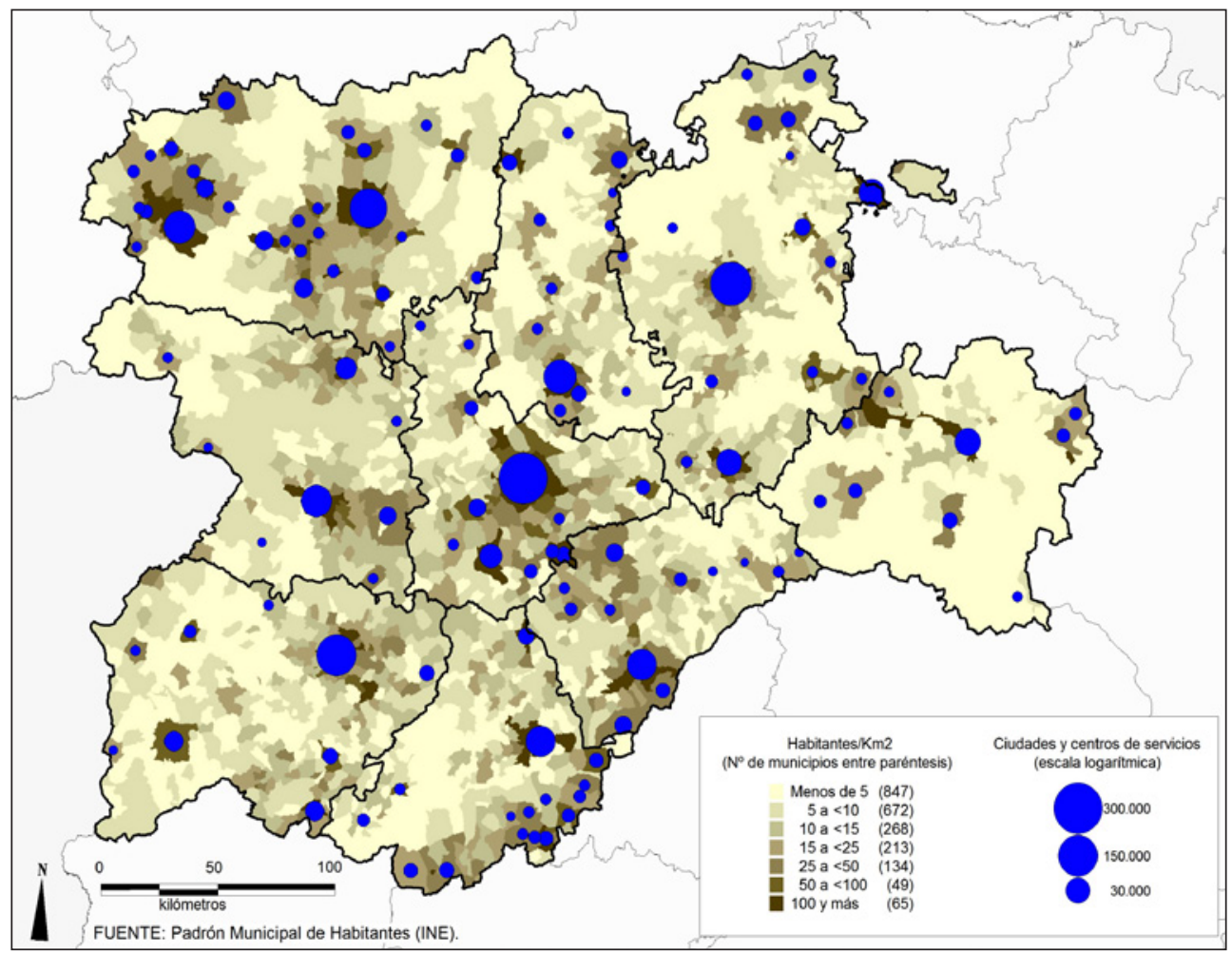

Fuente: Elaboración propia a partir de INE: Padrón Municipal de Habitantes.

\section{II.2. La reducción de las dotaciones de servicios}

En Castilla y León, dado el reducido número de habitantes y la dispersión del poblamiento en el medio rural, servicios de utilización frecuente como los financieros, comerciales, de ocio, sociales, sanitarios, etc., se encuentran ausentes en la mayoría de las localidades, obligando a la población a desplazarse a centros comarcales y ciudades. De entre estas actividades destacan por su reducida presencia las financieras. En 2003, el año anterior a la puesta en marcha del transporte a la demanda, 1.599 municipios no disponían de sucursales bancarias o cajas de ahorros, siendo la característica general en todos ellos su escaso número de habitantes -un promedio de 224- aunque en conjunto la población 
afectada ascendía a 358.198 personas. La cifra aumentó a 1.647 en 2011, el 74\% de los existentes, a la par que la de residentes había disminuido como consecuencia de la despoblación, si bien la diferencia era escasa -356.453- y por tanto su tamaño medio continuaba mermando, apenas 213 habitantes. La distribución espacial de las entidades financieras dista mucho de la correspondiente a la población y como era de esperar su presencia en los municipios de menor entidad, por debajo de los dos mil habitantes, tiende a reducirse. En estos municipios residían al finalizar la primera década del presente siglo un 60,8\% de los habitantes del medio rural y se localizaban el $86,3 \%$ de las entidades, un índice de apenas 267 residentes por oficina que hace presagiar una merma aún más rápida de su presencia al carecer de la masa crítica de demanda imprescindible. La evolución es disimilar entre provincias pese a que el aumento del número de municipios sin presencia de servicios financieros es común a seis de ellas, manteniéndose constante en León y habiéndose reducido en Segovia y Zamora (Tabla 1). En ambas provincias el crecimiento de urbanizaciones residenciales en los entornos capitalinos supuso la apertura de nuevas oficinas en los municipios beneficiados por el consiguiente aporte demográfico. Pero además, en gran parte del medio rural, la llegada de población extranjera frenó la despoblación hasta 2009 permitiendo así no solo el mantenimiento de las dotaciones existentes sino también su ampliación, tanto en el caso de los servicios financieros como en el de los restantes, razón por la cual el cierre de sucursales entre 2003 y 2011 fue inferior a lo que cabría esperar. La situación de carencia dotacional es no obstante más acentuada cuando el análisis se

Tabla 1

MUNICIPIOS Y POBLACIÓN SIN ACCESO DIRECTO A SERVICIOS FINANCIEROS (2003 Y 2011)

\begin{tabular}{|l|r|r|r|r|r|r|r|r|}
\hline \multirow{3}{*}{ Provincia } & \multicolumn{4}{|c|}{ Número de municipios } & \multicolumn{3}{c|}{$\begin{array}{c}\text { Población sin acceso directo } \\
\text { a servicios financieros }\end{array}$} \\
\cline { 2 - 10 } & $\begin{array}{r}\text { Sin servicios } \\
\text { financieros }\end{array}$ & \multicolumn{2}{|c|}{$\%$ sobre el total } & \multicolumn{2}{c|}{ Población } & \multicolumn{2}{c|}{$\%$ sobre el total } \\
\cline { 2 - 10 } & 2003 & 2011 & 2003 & 2011 & 2003 & 2011 & 2003 & 2011 \\
\hline Ávila & 173 & 177 & 69,76 & 71,37 & 29.542 & 25.700 & 17,89 & 14,88 \\
\hline Burgos & 256 & 275 & 69,00 & 74,12 & 35.379 & 45.680 & 10,03 & 12,16 \\
\hline León & 127 & 127 & 60,19 & 60,19 & 80.594 & 69.807 & 16,23 & 14,02 \\
\hline Palencia & 147 & 153 & 76,96 & 80,10 & 26.200 & 25.968 & 14,88 & 15,13 \\
\hline Salamanca & 272 & 304 & 75,14 & 83,98 & 61.498 & 72.852 & 17,72 & 20,64 \\
\hline Segovia & 158 & 156 & 75,60 & 74,64 & 25.512 & 26.737 & 17,09 & 16,29 \\
\hline Soria & 132 & 150 & 72,13 & 81,97 & 12.750 & 15.016 & 13,94 & 15,77 \\
\hline Valladolid & 147 & 150 & 65,33 & 66,67 & 28.347 & 25.887 & 5,66 & 4,84 \\
\hline Zamora & 187 & 182 & 75,40 & 73,39 & 58.376 & 48.806 & 29,09 & 25,24 \\
\hline Total & 1.599 & 1.674 & 71,13 & 74,47 & 358.198 & 356.453 & 14,44 & 13,93 \\
\hline
\end{tabular}

Fuente: Elaboración propia a partir de INE: Padrón Municipal de Habitantes y Caja España-Caja Duero: Datos Económicos y Sociales de las Unidades Territoriales de España. 
circunscribe a los espacios estrictamente rurales. Así, descartando del cómputo junto a las ciudades a los municipios enclavados en franjas periurbanas o de clara influencia urbana, la cantidad de los que carecían de oficinas bancarias o cajas de ahorros en 2011 era de 1.611 sobre un total de $2.072(78 \%)$ y afectaba a 309.287 habitantes, más de un tercio de los residentes en ese territorio ${ }^{3}$. El $45 \%$ de estas actividades se localizaban en centros de servicios pero ni siquiera todos los que ejercían tales funciones (distribución comercial, talleres, bares y restaurantes, etc.) contaban con ellas.

La necesidad de realizar desplazamientos como consecuencia de las carencias dotacionales no se limita a la reducida presencia de los servicios financieros en el medio rural, extendiéndose a otros de uso aún más generalizado como el abastecimiento, por ejemplo. Y es este déficit una de las principales causas que llevó a la puesta en marcha del transporte a la demanda, junto a la asimismo concentrada localización de servicios sanitarios y sociales. En el caso del comercio minorista la encuesta realizada en el año 2002 por miembros del Departamento de Geografía de la Universidad de Valladolid a residentes en municipios rurales de Castilla y León menores de tres mil habitantes indicaba que los viajes motivados por la necesidad de realización de compras eran comunes para la mayoría de los encuestados, un hecho manifiesto si se tiene en cuenta que en el 30,7\% de los municipios donde se enclavan esas localidades el comercio al por menor era inexistente y en otro $27,0 \%$ claramente insuficiente, limitándose a los bienes más básicos (alimentación). Los establecimientos especializados solamente estaban presentes en el 23,8\% de los casos y apenas en un $3,9 \%$ los consumidores declararon que el equipamiento minorista era el adecuado.

Esta situación se mantenía unos años después como indican los resultados de la segunda encuesta realizada en 2004 en localidades pertenecientes a municipios de entre 500 y 19.999 habitantes, donde si bien en el 79,5\% de los casos se cubrían las primeras necesidades, ello era posible gracias a la presencia de un comercio ambulante que llegaba al $84,6 \%$ de ellas y de ferias y mercados itinerantes en el 50,3\% $\%^{4}$. En ese año el $86,2 \%$ de los entrevistados indicaba la necesidad de realizar desplazamientos a centros de servicios o ciudades cercanas para suplir el déficit dotacional existente en sus lugares de residencia. Las carencias detectadas se extendían a todo tipo de equipamientos, entre ellos los destinados a satisfacer las necesidades de la población más envejecida, como son las residencias de ancianos, centros de día o los servicios de ayuda a domicilio, inexistentes o insuficientes en el $45-48 \%$ de los municipios rurales mayores de quinientos habitantes y en el 55\% de todos los menores de tres mil. Una situación que como es lógico se agravaba en las localidades de menor entidad y, en general, en todos los municipios del ámbito rural menores de dos mil habitantes (Figura 2), donde los desplazamientos por todos estos motivos afectaban al $89 \%$ de los residentes.

3 La tipología municipal utilizada diferencia entre el espacio rural profundo, centros de servicios de $1^{\mathrm{er}}, 2^{\mathrm{o}}$ y $3^{\text {er }}$ orden, áreas de influencia urbana, franjas periurbanas, ciudades y capitales. Una explicación de las variables utilizadas para establecer estas categorías en Castilla y León puede encontrarse en Martínez y Delgado, 2013.

4 Encuesta a los municipios menores de 3.000 habitantes en 2002 (Caballero y Delgado, 2002: 193-219). Encuesta a los municipios de 500 a 19.999 habitantes en 2004 (Delgado y Caballero, 2005: 585-598). 


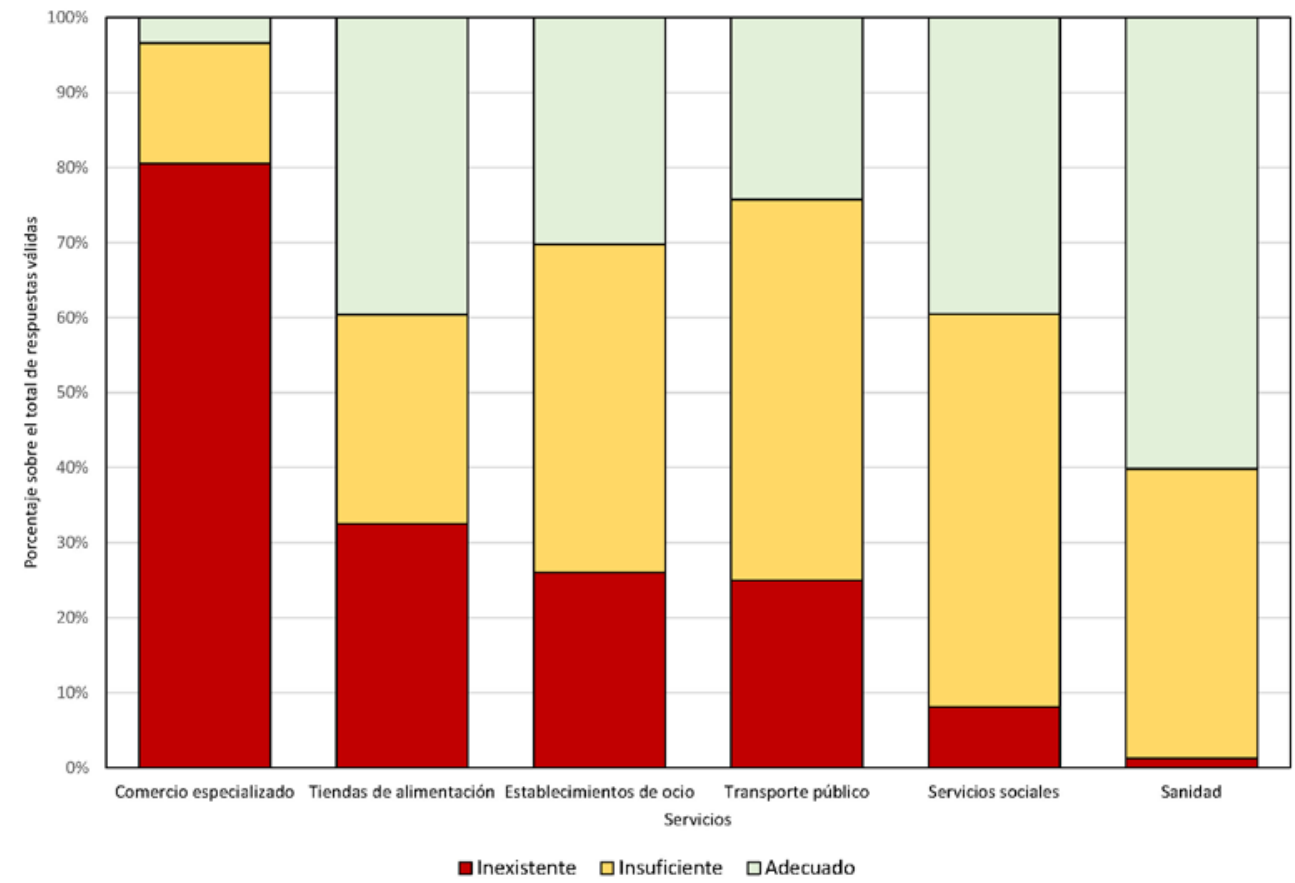

Fuente: Encuesta a los municipios menores de 3.000 habitantes (Caballero y Delgado, 2002).

\section{II.3. Situación del transporte de pasajeros por carretera y sobrecoste de los desplazamientos}

Pese a estas y otras necesidades, la baja densidad de población impedía el mantenimiento o la creación de las líneas de autocares precisas por su obvia falta de rentabilidad económica, a lo que se unía la problemática existente en aquellas localidades más alejadas de la red de carreteras nacionales. La localización de las estaciones de autobuses corresponde a las nueve capitales de provincia junto a otras ocho ciudades de la Región y dos grandes centros comarcales, discurriendo las principales líneas a lo largo de las carreteras nacionales que comunican estos núcleos entre sí o con otras capitales ajenas a la Comunidad ${ }^{5}$. La existencia de múltiples apeaderos tampoco resuelve el problema de accesibilidad, dado que los viajeros han de desplazarse por sus propios medios desde su localidad hasta aquella donde se ubica este. Respondiendo a la lógica, el déficit de transporte público en el medio rural se intensificaba en los espacios intersticiales definidos por la red de carreteras nacionales (De las Rivas, 2010) y así queda reflejado en las encuestas ya citadas realizadas en los municipios de menor

5 Las ciudades son Aranda de Duero (Burgos), Astorga, La Bañeza, Ponferrada, Villablino, (León), Béjar, Ciudad Rodrigo (Salamanca) y Benavente (Zamora) y los centros de servicios Guardo (Palencia) y Cuellar (Segovia). Sobre la red de carreteras y su incidencia en la dinámica económica, véase Martínez y Luengo, 2004. 
entidad demográfica. Ni siquiera las elevadas subvenciones concedidas por la Junta de Castilla y León en esos años (3.000.000 € en 2004) y el casi medio millón anual de expediciones de transporte de viajeros realizadas fueron suficientes para paliar la demanda expresada por los usuarios.

Casi una cuarta parte de los municipios que en 2002 no superaban los 3.000 habitantes carecían de transporte público, siendo además el disponible insuficiente en la mitad de los restantes. La situación más problemática afectaba a los de menor entidad, pero ni siquiera en los de mayor tamaño la prestación de estos servicios se consideraba adecuada por parte de sus habitantes. Los datos registrados por la encuesta realizada en el año 2004, donde se efectuaron preguntas más específicas sobre el tema, muestran incluso un déficit más acentuado. Teniendo en cuenta que se eliminaron del universo censal los de menor población, incluyendo en cambio centros comarcales y ciudades de hasta 19.999 habitantes, el hecho de que solamente en un $32,6 \%$ de los casos se considerase suficiente el servicio de transporte colectivo resulta bastante preocupante.

Algunos ayuntamientos - un 29\% de los encuestados en 2004- habían intentado suplir a través de iniciativas propias tales carencias, pero los resultados fueron negativos en la mayor parte de los casos, salvo en el aspecto relativo al transporte escolar. Por una parte, la disponibilidad presupuestaria limita las posibilidades de actuación municipal, siendo necesarias subvenciones provenientes de otras administraciones (diputaciones provinciales y Junta de Castilla y León). Además, la puesta en marcha de iniciativas locales para solventar situaciones concretas se encuentra dificultada por la normativa sobre transporte de pasajeros, que obliga a la obtención de una licencia. Aunque esta debe ser otorgada por el ayuntamiento, existe un número máximo de licencias dependiente de la Consejería competente y establecido en función del volumen de población, entre otros parámetros, lo cual reduce drásticamente las posibilidades reales. Es cierto que la actual Ley de Transporte permite autorizar, siempre previo informe de la Consejería y de forma excepcional, la concesión de licencias para auto taxis (hasta cinco plazas) o vehículos de mayor capacidad cuando las características geográficas, demográficas o económicas de la zona lo justifiquen, así como en ausencia de servicios de transporte colectivo que cubra la demanda existente. Pero los intereses de vecinos y de la administración local chocan frontalmente con los de propietarios de taxis, dificultando la obtención de nuevas licencias. Y aunque la legislación actual permita, al menos en teoría, la creación de tales servicios, obliga a la profesionalización de los prestatarios, con el coste que ello supone para el implicado. En definitiva, se trata de un círculo cerrado, pues la misma escasez de usuarios impide también en este caso la amortización de las inversiones. En cuanto a los acuerdos particulares entre vecinos para realizar desplazamientos, se encuentran supeditados a la disponibilidad de un vehículo adecuado y a su mantenimiento, aspecto en el cual tampoco puede ayudar el ayuntamiento, por lo que cualquier actividad en este sentido queda limitada a la buena voluntad de los propietarios de vehículos.

En consecuencia, allí donde no existe o es insuficiente el transporte colectivo convencional los vecinos sufren directamente el sobrecoste de los desplazamientos, cuya diferencia con respecto al correspondiente a la población urbana puede llegar a ser bastante elevada según el tipo de familia y modelo de poblamiento. Efectivamente, en los municipios menores de 10.000 habitantes el gasto medio por hogar en transporte, sumando la compra de vehículos, su utilización y el transporte público, suponía en 2011 el 13,9\% del presupuesto familiar, 
mientras en los mayores de 100.000 se reducía al 10,5\%, siguiendo una tendencia descendente según el tamaño, con una destacable diferencia entre la zona más densamente poblada $(10,7 \%)$ y la diseminada $(14,7 \%)$. Si eliminamos del cómputo la adquisición del vehículo las distancias entre ambos ámbitos territoriales son incluso mayores, correspondiendo al rural el 10,5\% del gasto medio frente al 7,9\% en los grandes municipios (Fundación Encuentro, 2012: 348-350). Aunque el gasto total ha ido reduciéndose en todos los casos como consecuencia de la crisis económica y se ha modificado su distribución por subgrupos las diferencias relativas se mantenían en 2013 , siendo un $8,3 \%$ superior el rural al urbano y en las zonas con densidad baja o media un 6,4 y 5,4\% mayor con respecto a las de densidad más elevada. Las encuestas realizadas no profundizaron en este aspecto, pero análisis efectuados en áreas rurales del Reino Unido indican que las diferencias pueden llegar a ser de un 19-22\% para las parejas de pensionistas que residan en pequeños pueblos, un 18-24\% para parejas sin hijos y un 15-18\% en parejas con dos hijos (Smith et al., 2010: 98). De ahí que tras la solicitud de subvenciones, expresada por el $70 \%$ de los municipios, la petición de un cambio en la normativa o de un sistema alternativo que modificase esta situación fuera el segundo punto en el que mayor énfasis se hacía en el ámbito rural, indicándolo así el 60\% de los encuestados.

Las encuestas realizadas en 2002 y 2004, aun basándose en una muestra del total de municipios, permitieron cartografiar a grandes rasgos los sectores donde la necesidad se sentía con mayor intensidad, coincidiendo estos con áreas localizadas en espacios intersticiales de la red nacional de carreteras. Otros datos objetivos, como la presencia de taxis y la disponibilidad de vehículos particulares pueden ayudar también en este sentido. Solamente en el $17 \%$ de los municipios rurales existían paradas de taxis, eliminados del cómputo las ciudades y sus entornos periurbanos, y un $22 \%$ de ellos eran centros comarcales con más de dos mil habitantes. La disponibilidad de vehículos particulares presentaba grandes variaciones, dependiendo en general del grado de envejecimiento demográfico; con un promedio regional de 40,7 vehículos por cada cien habitantes en 2002, en el medio urbano la tasa era de 41,0 y en el rural descendía a 38,7 no siendo escasos aquellos municipios donde ni siquiera se alcanzaban los 30 (el 16\% de los menores de dos mil habitantes). Aunque la diferencia entre espacios urbanos y rurales pueda parecer reducida, debe considerarse que en los segundos se carece de la elevada movilidad que los medios de transporte públicos otorgan a los residentes en las ciudades. La yuxtaposición de estos datos permite vislumbrar amplias zonas donde la demanda de transporte se encontraba claramente insatisfecha, como sucedía a lo largo de la franja fronteriza zamorana y salmantina (penillanuras de Aliste y Sayago), parte del sector occidental abulense o del nororiental soriano, por ejemplo.

\section{II.4. Sistema de ayudas al mantenimiento de los servicios de transporte rural}

La intervención de la Administración era por tanto más una obligación que una opción para suplir las carencias descritas y, en este sentido, fueron varias las actuaciones desarrolladas por la Junta de Castilla y León. El sistema de ayudas a la explotación de servicios deficitarios de transporte surgió en 1988 con el objetivo de favorecer la fijación de población en zonas rurales, posibilitando su acceso a los servicios sanitarios, sociales y culturales inexistentes en sus localidades de residencia. Se trataba, principalmente, de mantener interconectados los pequeños núcleos de población con las cabeceras de comarca, allí donde la demanda 
no cubría el coste del servicio. Cierto es que con anterioridad a esa fecha habían tenido lugar actuaciones encaminadas a la promoción del transporte rural, basadas en la flexibilización de las condiciones para obtener concesiones de servicios y para otorgar autorizaciones a vehículos, así como ayudas para su renovación, pero sus resultados no fueron los deseados. Por ello y al amparo de la Ley de Ordenación de Transportes Terrestres de 1987, y del mismo Estatuto de Autonomía, considerando este servicio como interés general, se emite el Decreto para establecer ayudas al transporte rural de viajeros, cuyo Artículo $1^{\circ}$ indicaba claramente las nuevas líneas de actuación: "La Junta de Castilla y León, por medio de la Consejería de Fomento, podrá acordar la creación, mantenimiento o ampliación de cualquier clase de servicio de transporte de viajeros de interés general que tenga como objetivo el asegurar la movilidad de los residentes en áreas rurales, carentes de dicho servicio esencial o que existiendo se preste con déficit permanente no imputable a la mala gestión empresarial» ${ }^{6}$.

Desde el primer momento los objetivos se centraron en las zonas menos pobladas, estableciendo incluso un umbral máximo de densidad de 25 habitantes por $\mathrm{km}^{2}$. Las ayudas iban dirigidas a los titulares de las concesiones de explotación otorgadas por la Junta de Castilla y León o por el Estado, siempre y cuando las rutas transitasen por itinerarios rurales de la Región, así como para la financiación de nuevos servicios que cumpliesen las mismas condiciones. Es de destacar que en este último caso la normativa señalaba, entre la documentación a aportar por el solicitante, la "petición expresa del Ayuntamiento, Diputación o Entidad Local del que dependan el núcleo o núcleos afectados» ${ }^{7}$. Los criterios posteriores para la concesión de ayudas tuvieron en cuenta además de la situación de déficit y las subvenciones recibidas otros parámetros no menos interesantes, como el interés social y las necesidades de movilidad de los residentes, el volumen de población atendida, la incorporación de tecnologías que facilitaran la accesibilidad a personas que la tenían reducida, la aplicación de programas de gestión medioambiental y, lo que se traducirá posteriormente en un proyecto más específico, las propuestas que permitiesen la mejor gestión del transporte a la demanda. La importancia dada a este tipo de ayudas se refleja en el incremento de las inversiones durante los primeros años del nuevo siglo. En efecto, los $931.000 €$ de financiación aportados en 1998 se triplicaron en apenas un quinquenio, alcanzando tres millones en 2003 y llegando a 13,5 en 2008 (FUNDETEC, 2008: 158), siguiendo una orientación territorial bastante acorde con las ideas expuestas ${ }^{8}$.

Pero seguían siendo precisas actuaciones más imaginativas y El Plan de Coordinación del Transporte Rural de la Consejería de Fomento puesto en marcha en 2001 fue una de ellas, pues entre sus objetivos destacaba el asegurar la movilidad de los residentes en zonas rurales con menos de dos mil habitantes alejadas de las ciudades mediante subvenciones a las empresas de transporte para el mantenimiento de líneas de autobuses deficitarias, la

6 Decreto 87/1988, de 12 de mayo, de la Junta de Castilla y León, por el que se establecen ayudas a los transportes públicos de viajeros de carácter rural, para compensar sus obligaciones de servicio público (BOCYL de 18 de Mayo de 1988) y Ley 16/1987, de 30 de Julio, de Ordenación de los Transportes Terrestres.

7 Orden FOM/1751/2003, de 22 de diciembre, por la que se regulan las ayudas a la explotación de servicios deficitarios de transporte público permanente regular de uso general de viajeros por carretera de carácter rural.

8 El mayor porcentaje correspondiente a la provincia de León se justifica por la mayor demanda existente en términos absolutos, especialmente en la comarca de El Bierzo. El sur de Ávila, norte de Burgos, Sanabria, la Montaña Palentina, Salamanca y el sur de Soria también habían sido incluidas en fases posteriores del plan que no llegaron a desarrollarse. 
optimización de rutas y la adecuación de horarios a las necesidades de los vecinos según el tipo de servicios (educación, sanidad, ferias y mercados, cultura y ocio). Dirigido a comarcas concretas (El Bierzo, centro de Palencia y zona de Aliste), se trataba en realidad de un intento por coordinar y potenciar medidas ya existentes anteriormente, las destinadas a financiar la explotación de determinadas líneas de transporte de pasajeros en el medio rural que resultaban deficitarias económicamente aunque socialmente necesarias.

Con todo, la subvención al mantenimiento o creación de líneas de autobús en áreas rurales representaba un esfuerzo inversor difícil de mantener en una región como Castilla y León, con un elevado número de pequeños núcleos de población muy dispersos y una población envejecida y decreciente. Baste citar que en 2004 existían 156 concesiones de servicios regulares autonómicos con itinerarios y horarios fijos y otro centenar de autorizaciones para transportes especiales, de horarios más flexibles (Junta de Castilla y León, 2004). En las líneas regulares los itinerarios se tornaban excesivamente largos, al intentar enlazar el mayor número posible de entidades, llevando pese a ello un elevado número de plazas sin ocupar. No se alcanzaba por tanto una rentabilidad económica, pero tampoco se conseguía satisfacer las demandas de los pasajeros, al implicar cada desplazamiento un coste económico y consumo de tiempo excesivos. Era preciso encontrar otra alternativa.

\section{FUNCIONAMIENTO Y EXPANSIÓN DEL TRANSPORTE A LA DEMANDA}

En principio los servicios de transporte a la demanda surgidos en la Unión Europea se contrataban off-line mediante reserva previa con un margen de tiempo establecido. Posteriormente se fueron introduciendo las nuevas tecnologías on-line de AVM (Advanced Vehicle Monitoring) que permiten flexibilizar aún más el servicio, utilizar el tipo de vehículo más adecuado e informar en todo momento al viajero, siendo estas últimas las adoptadas en Castilla y León siguiendo el modelo de demostrada eficiencia implantado en el Reino Unido (Brake et al., 2004). El Servicio Público de Transporte a la Demanda, proyectado en fase de pruebas desde mayo de 2004 y que fue aumentando con rapidez el número de municipios beneficiados en los años siguientes, comenzando por las áreas periféricas de la Región, supuso una innovación destacable en el capítulo del incremento de la accesibilidad. Durante el período de pruebas realizado en la provincia de Ávila demostró la existencia de una demanda en principio reducida, con 353 reservas en 25 semanas (14 reservas semanales), pero como cualquier otro servicio, el conocimiento de su existencia y el efecto reclamo dieron lugar al rápido incremento de su utilización en un corto periodo de tiempo.

\section{III.1. Las bases del sistema de transporte a la demanda}

El sistema de transporte a la demanda se creó con un triple objetivo, buscando nuevas prestaciones para favorecer al usuario, al operador y a la propia Administración. Los usuarios disponen gracias a él de transporte cuando se precisa allí donde no existen líneas convencionales o son insuficientes, garantizándose la prestación y rapidez al eliminar paradas innecesarias e informándose en tiempo real de cuándo será la llegada a cada núcleo. El operador ve reducidos sus costes por la optimización de los recorridos según las solicitudes y aumentar el número de viajeros al mejorar el servicio, pudiendo adaptar además el tipo de vehículo a los requeri- 
mientos concretos. En tercer lugar, la Administración puede analizar y controlar la calidad de este. Las tareas de atención y coordinación siguen el modelo de los Mobility Centers o Travel Dispatch Centers, localizándose en el Centro Virtual de Transporte a la demanda -CVTD- de la Administración de Transportes de la Comunidad, donde se realizan las reservas de ida y vuelta llamando a un número gratuito con al menos veinticuatro horas de antelación, abonándose al comienzo del viaje. El precio del servicio es social -un euro el servicio de ida y vuelta hasta 2012 y el doble desde mediados de ese año- y se aplica una tarifa plana independiente del kilometraje recorrido por cada usuario, para hacerlo accesible a toda la población. Las rutas, horarios y frecuencias se establecen buscando la compatibilidad en los desplazamientos motivados por razones de salud -visitas a centros médicos-, abastecimiento -mercados semanales-, servicios administrativos y financieros o para que el usuario puede enlazar con otros medios de transporte, ajustando los horarios con el de los autobuses que comunican la cabecera comarcal con la capital provincial. Una vez completadas la reservas suficientes para generar el viaje el CVTD se pone en contacto a su vez con el operador correspondiente, manteniéndose una comunicación telemática durante la prestación del servicio y transmitiendo en tiempo real al usuario la información necesaria mediante terminales instalados en las paradas (hora de llegada del vehículo, plazas libres disponibles -sin reserva- y posibles incidencias). Junto a sus objetivos iniciales el sistema de transporte a la demanda ha servido además a otros fines, como la reducción en lo posible de desplazamientos en vehículos privados y con ella el gasto familiar, la accidentabilidad y las emisiones de $\mathrm{CO}_{2}$ (Junta de Castilla y León, 2008: 82), coincidiendo en ello con otras iniciativas europeas similares (Laws et al., 2009).

La primera variable a considerar para el trazado de las rutas es el modelo de poblamiento rural y, en especial, la distribución de los núcleos de población menos habitados, que son también los más envejecidos y donde con mayor intensidad se sufre la carencia de servicios, incluyendo el de transporte regular. En cada ruta ha de existir una cabecera con los equipamientos y dotaciones suficientes para satisfacer las necesidades de esa población, por lo que se intenta coincidan con los centros de servicios más desarrollados, conformando en torno a ellos las Zonas de Transporte a la Demanda -ZTD-. No obstante, y en áreas de escasa población, esas cabeceras recaen en localidades de reducida entidad, apenas un millar de habitantes, pero con unos servicios mínimos asegurados, lo cual contribuye asimismo a su mantenimiento. Los viajes se programan en función de las reservas realizadas, buscando la optimización de recursos mediante la elección en cada caso del vehículo más apropiado para cubrir el mayor número de plazas posible, e informando en todo momento al usuario de la hora de llegada del mismo y de la disponibilidad de plazas sin reserva, todo ello gracias a paneles informativos en cada parada. La fase de pruebas se circunscribió a siete localidades de la provincia de Ávila, para extenderse posteriormente a otras comarcas, siempre y cuando no fuera posible el mantenimiento de un servicio convencional ${ }^{9}$.

9 Las localidades abulenses donde primero se implantó son La Zarza, Solana, Los Narros, Mazarinos, Serranía, El Barco de Ávila y Santa Lucía. A finales de noviembre de 2004 se extendió la oferta a la Montaña de Riaño, donde 8 de sus 25 ayuntamientos carecían de transporte público, beneficiando en una primera fase a 4.800 personas y en el mismo año alcanzó a las comarcas zamoranas del Aliste y Sanabria, en 76 pueblos con un total de 6.200 habitantes. En verano de 2005 el servicio se había extendido a las provincias restantes, llegando a Medina de Pomar en Burgos, Cervera de Pisuerga en Palencia, la Alberca en Salamanca, Cuellar y Carbonero el Mayor en Segovia, Ágreda, Almazán y Arcos del Jalón en Soria y Mota del Marqués en Valladolid, continuando su expansión hasta 2012. 


\section{III.2. Delimitación de las Zonas de Transporte a la Demanda y expansión del servicio}

En los diez primeros años de funcionamiento del transporte a la demanda el servicio se expandió a las nueve provincias de la Comunidad Autónoma, superando el centenar de zonas operativas y disponiendo en cada una de ellas de diferentes rutas alternativas según las necesidades concretas del momento, sobrepasándose las ochocientas. Los recorridos o expediciones a lo largo de tales rutas pueden ser varios a la semana por lo que su cifra total es todavía mayor, cercana a los tres mil (en 2011 fueron 2.851), aunque con las oscilaciones estacionales lógicas a lo largo del año, dado que la demanda desciende entre un 40 y $60 \%$ durante el invierno frente a los máximos estivales. Cada ruta enlaza las pequeñas localidades carentes de otros servicios de transporte con las cabeceras de las ZTD, ubicadas en los mencionados centros comarcales con las dotaciones requeridas que incluyen, junto al equipamiento comercial, financiero y administrativo, los servicios sanitarios y sociales de mayor demanda.

Para satisfacer esas condiciones se tuvieron en cuenta los límites de las Zonas Básicas de Salud y los Centros de Acción Social-CEAS- de los cuales dependen los servicios sociales básicos organizados en Zonas de Acción Social (Figuras 3 y 4), coincidentes en gran parte con los límites escogidos para el trazado de las rutas desde las cabeceras, salvo algunos desajustes derivados a su vez de las zonas de salud que no siempre respetan los bordes provinciales. En su conjunto, el transporte a la demanda llegaba en 2014 a 3.551 localidades atendiendo a 395.464 habitantes, sin contar los residentes en las cabeceras de cada ruta. Teniendo en cuenta toda la población conectada la cifra asciende a 1.007.269 y en sus primeros diez años de existencia ha tenido 2,7 millones de viajeros.

La organización territorial y funcional del sistema de servicios sociales se basa por tanto en las Zonas Básicas de Salud, siendo su eje fundamental los CEAS, estructuras organizativas de primer nivel a los cuales se adscriben los Equipos de Acción Social Básica dependientes de las entidades locales ${ }^{10}$. En cada una de las Zonas de Acción Social existe un CEAS con funciones de información, orientación, asesoramiento, desvío de casos, prevención, acceso a los servicios sociales, seguimiento de las prestaciones, detección de necesidades, elaboración de propuestas de actuación, participación social, etc., por lo que suponen un punto de referencia para la población y, en consecuencia, han de contar con una elevada accesibilidad. Las zonas de transporte integran una o varias de estas zonas de salud y buscan generar o aprovechar áreas de influencia en torno a centros de servicios con una demanda potencial en torno a diez mil habitantes, aunque frecuentemente, debido a la baja densidad de población y con el objeto de no incrementar el exceso las distancias, la cifra es inferior. El tipo de poblamiento y las comunicaciones son por tanto elementos fundamentales en el trazado de estas zonas, que también intentan coincidir con las Zonas Básicas de Salud y adecuar horarios y fechas, introduciendo modificaciones en el calendario de los servicios sanitarios para centralizarlos en aquellos días en que arriban expediciones, por regla general tres a la semana (FUNDETEC, 2008: 159). Puesto que los mapas de las Zonas de Acción Social y de Salud se superponen en gran medida la adopción de estos parámetros no supuso grandes problemas, en especial considerando que las segundas son más numerosas por su menor superficie y una ZAS puede englobar varias (Figuras 3 y 4). Una vez configurada cada ZTD y los servicios de transporte existentes la

10 Ley 16/2010, de 20 de diciembre, de servicios sociales de Castilla y León (BOE de 8 de enero de 2011). 
Administración se pone en contacto con los concesionarios que operan en ella para proponer las nuevas rutas, modificando en consecuencia las líneas regulares o sustituyéndolas en su totalidad, valorando asimismo las alegaciones municipales (FUNDETEC, 2008: 160-161).

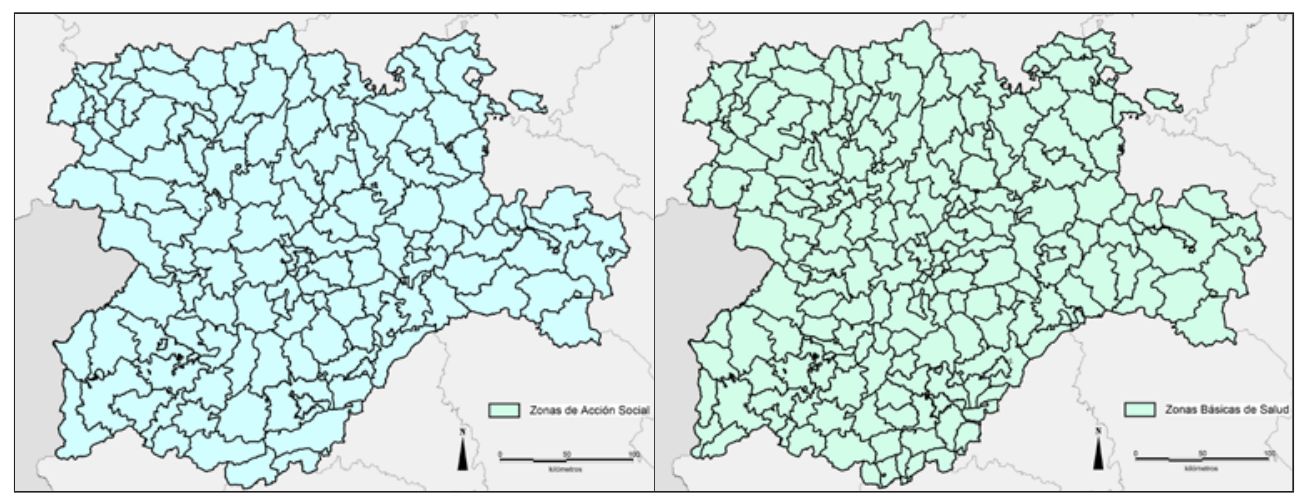

Fuente: elaboración propia a partir de Junta de Castilla y León: Guía de Recursos Sociales de Castilla y León 2014.

La creación de las ZTD mantuvo una evolución muy rápida en los cuatro primeros años de su existencia y a finales de 2007 ya estaban operativas 59, más de la mitad del total alcanzado (Tabla 2). Pero el proceso se ralentizó posteriormente y entre 2009 y 2011 la media anual se redujo a la mitad, añadiéndose la última de las actualmente existentes en 2012. La cobertura final resultante es muy desigual, con provincias como Segovia, Soria y Valladolid donde casi la totalidad de sus municipios rurales disponen de acceso a este servicio y otras, caso de Burgos y Salamanca, que no alcanzan ni la mitad. Pese a ello las áreas tradicionalmente más desfavorecidas por su menor densidad de población, como sucede con las penillanuras occidentales salmantinas y zamoranas, la mencionada provincia de Soria o el norte burgalés, palentino y buena parte del leonés, así como amplias áreas rurales abulenses están asimismo cubiertas por el transporte a la demanda. En León y Zamora los municipios sin ZTD poseen densidades más elevadas y corresponden o se encuentran cercanos y bien comunicados con importantes centros de servicios, como La Bañeza, Bembibre, Cacabelos, Fabero y La Robla en la primera provincia y Benavente y Toro en la segunda. Quedan al margen, sin embargo, la mayor parte de Burgos y Salamanca, donde salvo por las cuatro ciudades existentes y sus periurbanos - ambas capitales, Aranda de Duero y Miranda de Ebro-, en la mayoría de los municipios no se superan los 10 habitantes por $\mathrm{km}^{2}$. En estas áreas estaban previstas o en fase de estudio nuevas ZTD pero la crisis de 2008 y las consiguientes políticas de recortes presupuestarios supusieron el freno a la continuidad del proyecto ${ }^{11}$.

11 El coste de mantenimiento del servicio de transporte a la demanda para la Junta de Castilla y León era de unos 16 millones de euros anuales en 2011, dividido a partes iguales entre la central de reservas y los sistemas tecnológicos utilizados, por un lado, y los costes de explotación abonados a las empresas concesionarias, por otro. Para poder mantenerlo en activo, además de la reorganización indicada, se procedió a reducir las ayudas a las líneas convencionales deficitarias con itinerarios fijos, que en solo un año cayeron el 30\% (Consejería de Fomento y Medio Ambiente). 
Tabla 2

CRONOLOGÍA DE LAS ZONAS DE TRANSPORTE A LA DEMANDA

\begin{tabular}{|c|c|c|c|c|c|c|c|c|c|c|c|}
\hline \multirow{2}{*}{ Provincia } & \multicolumn{9}{|c|}{ Año de la puesta en marcha } & \multirow{2}{*}{\begin{tabular}{|c|} 
Operativas \\
en 2014
\end{tabular}} & \multirow{2}{*}{$\begin{array}{c}\text { En } \\
\text { estudio }\end{array}$} \\
\hline & 2004 & 2005 & 2006 & 2007 & 2008 & 2009 & 2010 & 2011 & 2012 & & \\
\hline Ávila & 2 & 0 & 1 & 3 & 0 & 3 & 1 & 1 & 0 & 11 & 0 \\
\hline Burgos & 0 & 1 & 3 & 3 & 1 & 2 & 1 & 0 & 0 & 11 & 3 \\
\hline León & 1 & 2 & 4 & 2 & 1 & 2 & 1 & 2 & 0 & 15 & 0 \\
\hline Palencia & 0 & 1 & 2 & 1 & 2 & 0 & 1 & 2 & 0 & 9 & 0 \\
\hline Salamanca & 0 & 1 & 2 & 1 & 3 & 1 & 1 & 0 & 1 & 10 & 1 \\
\hline Segovia & 0 & 2 & 1 & 2 & 2 & 0 & 1 & 0 & 0 & 8 & 2 \\
\hline Soria & 0 & 3 & 2 & 2 & 1 & 1 & 2 & 0 & 0 & 11 & 1 \\
\hline Valladolid & 0 & 1 & 3 & 4 & 4 & 2 & 2 & 2 & 0 & 18 & 0 \\
\hline Zamora & 2 & 2 & 3 & 2 & 1 & 1 & 1 & 0 & 0 & 12 & 1 \\
\hline Total & 5 & 13 & 21 & 20 & 15 & 12 & 11 & 7 & 1 & 105 & 8 \\
\hline
\end{tabular}

Fuente: elaboración propia a partir de Junta de Castilla y León: Balance del servicio de transporte a la demanda a 15-04-2014.

Tabla 3

REORGANIZACIÓN DE LAS RUTAS Y EXPEDICIONES EN LAS ZTD (2014)

\begin{tabular}{|l|r|r|r|r|r|r|}
\hline \multirow{2}{*}{ Provincia } & \multirow{2}{*}{ ZTD } & \multirow{2}{*}{ Poblaciones } & \multirow{2}{*}{ Rutas } & \multicolumn{3}{c|}{ Expediciones } \\
\cline { 6 - 8 } & & & & \multirow{2}{*}{ Semanales } & \multicolumn{2}{c|}{ Reorganizadas } \\
\cline { 6 - 8 } & & & & & \multicolumn{1}{c}{$\mathrm{N}^{\circ}$} & \multicolumn{1}{c|}{$\%$} \\
\hline Ávila & 11 & 351 & 84 & 305 & 124 & 40,7 \\
\hline Burgos & 11 & 641 & 117 & 375 & 124 & 33,1 \\
\hline León & 15 & 695 & 161 & 550 & 264 & 48,0 \\
\hline Palencia & 9 & 378 & 89 & 321 & 75 & 23,4 \\
\hline Salamanca & 10 & 278 & 66 & 231 & 118 & 51,1 \\
\hline Segovia & 8 & 272 & 61 & 200 & 87 & 43,5 \\
\hline Soria & 11 & 416 & 80 & 288 & 151 & 52,4 \\
\hline Valladolid & 18 & 232 & 86 & 319 & 80 & 25,1 \\
\hline Zamora & 12 & 295 & 67 & 210 & 108 & 51,4 \\
\hline Total & 105 & 3.558 & 811 & 2.799 & 1.131 & 40,4 \\
\hline
\end{tabular}

Fuente: elaboración propia a partir de Junta de Castilla y León: Balance del servicio de Transporte a la demanda a 15-04-2014.

En 2011 las necesidades de ahorro implicaron una reducción, si no de las ZTD, sí del número de expediciones semanales, a la par que se reconfiguraron los itinerarios para optimizar los recorridos. La Consejería de Fomento y Medio Ambiente de la Junta de Castilla y León procedió a la reorganización del sistema, lo que supuso el cambio de horarios y la reducción de frecuencias, ajustando ambos en la medida de lo posible a la demanda real detectada en los años precedentes para así aprovechar mejor los recursos disponibles (Tabla 3). Aunque las 105 ZTD existentes se mantuvieron activas (Figura 5) y el transporte asegurado para todas 
las localidades ya incluidas en el servicio, a mediados de 2013 el número de expediciones era ya un $40 \%$ inferior al existente tres años antes y así se ha mantenido en 2014. Para realizar estos cambios se priorizó la accesibilidad a los servicios más básicos, como la sanidad y el abastecimiento (se han tenido en cuenta los días de mercado, por ejemplo) en detrimento de los dedicados al ocio, respondiendo asimismo a la intensidad semanal de su uso. El mayor número de llamadas solicitando reservas se produce entre semana, agrupando el $64 \%$ del total los martes, miércoles y jueves -en torno al $21 \%$ del total cada día-, descendiendo los lunes y viernes -18 y $15 \%$ - y limitándose a un $3 \%$ los fines de semana ${ }^{12}$. Con todo, tanto el número de rutas como el de poblaciones atendidas se han mantenido constantes.

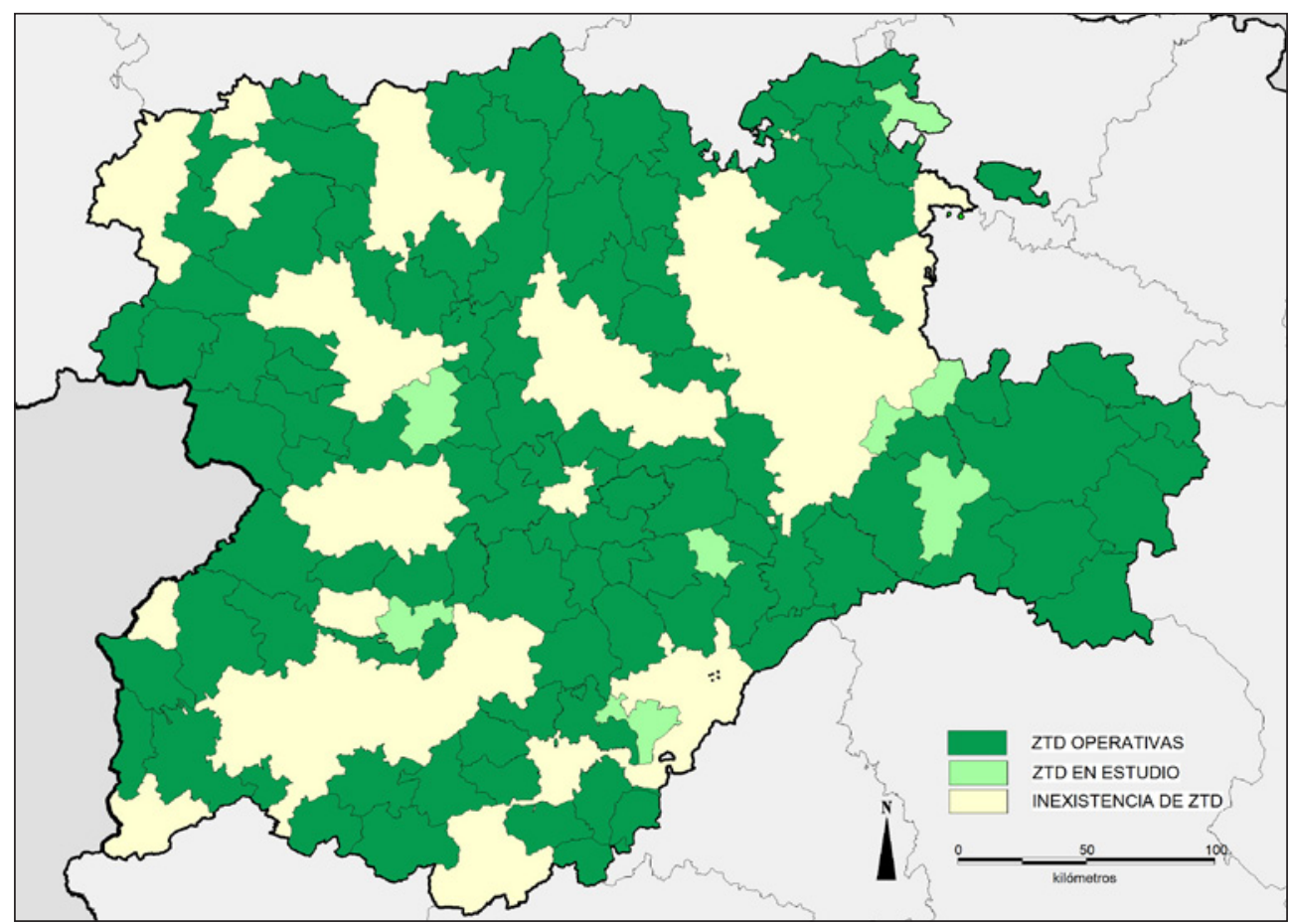

Fuente: elaboración propia a partir de Junta de Castilla y León: Balance del servicio de Transporte a la demanda a 15-04-2014.

Los resultados del servicio de transporte a la demanda pueden calificarse sin duda de positivos, al menos con anterioridad a la reducción de la oferta sufrida los últimos años. A escala de la Comunidad Autónoma la opinión de los usuarios en 2009, según la encuesta realizada a los viajeros que lo utilizaron entre enero y noviembre de ese año, era muy favorable ${ }^{13}$. Sobre una

12 Según información referida a julio de 2013 aportada por la Consejería de Fomento y Medio Ambiente.

13 Encuesta aleatoria a 4.200 usuarios realizada por encargo de la Consejería de Fomento y Medio Ambiente. 
puntuación de 10 el grado de satisfacción global alcanzó el 9,5 sin diferencias apreciables derivadas de las necesidades específicas en cada ZTD o de las características de los usuarios (sexo y edad $)^{14}$. En 2012 el primero de estos índices había bajado pero se mantenía muy alto $(9,0)^{15}$, aunque los últimos recortes efectuados han afectado sin duda ese dictamen y, si bien no se han efectuado nuevas encuestas para conocer el grado de incidencia de los mismos en el conjunto de Castilla y León, la realizada en la provincia de Segovia, cuyo ejemplo se analiza en el último epígrafe de este artículo, muestra que el 54\% de la población del medio rural considera que el transporte público en general es insuficiente pese a que el $77 \%$ de las localidades cuentan con este sistema (Martínez y Moreno, 2014: 209-233). Hay que tener presente que el usuario tipo tiene unas necesidades elevadas de desplazamiento debido a las ya indicadas carencias dotacionales en las pequeñas poblaciones rurales y la reducción de las frecuencias de los viajes incide claramente en su nivel de satisfacción. Se trata de personas de elevada edad, superando un $64 \%$ los 65 años y otro $28 \%$ los 50 , la mayoría mujeres $-67 \%$ - y la mitad de todos ellos $-51 \%$ - se desplazan al menos una vez a la semana gracias a este servicio, al carecer de vehículo propio. Desde el punto de vista de la economía y también antes de la reorganización del sistema los resultados fueron asimismo destacables, pues la sustitución de líneas regulares por las adaptadas a la demanda real supuso la reducción del kilometraje en un 67\% anual ya en 2007, de acuerdo a estimaciones de la Junta de Castilla y León.

\section{EL TRANSPORTE A LA DEMANDA EN LA PROVINCIA DE SEGOVIA}

El análisis detallado de las necesidades de transporte de viajeros derivadas del modelo de poblamiento, localización de los centros comarcales, densidades de población, red de carreteras y otras variables que inciden en la delimitación de las ZTD a escala de Castilla y León sería demasiado prolijo para desarrollarse en estas páginas. En su lugar se ha optado por centrarlo en la provincia de Segovia, donde la variedad de situaciones que incluye áreas con un poblamiento relativamente denso, como sucede en gran parte de Tierra de Pinares y el entorno capitalino, y otras con mínimos, caso del sector nororiental, sirve de ejemplo de la problemática general. Al igual que para el conjunto de la Comunidad la instauración del servicio de transporte a la demanda fue paulatina, comenzando por aquellas comarcas donde la necesidad era más sentida y no podía ser satisfecha por la oferta de las líneas convencionales o su mantenimiento constituía un coste excesivo. Las primeras cabeceras elegidas para las ZTD se localizaron en Tierra de Pinares: Carbonero el Mayor y Cuéllar en 2005, Cantalejo en 2006 y Nava de la Asunción en 2007. En ese mismo año se creó en el sector oriental, con poblamiento más disperso, la de Riaza y uno después la de Sepúlveda. También en 2007 surge la ZTD de Navafría, llegando el turno en 2010 a Sacramenia, una comarca con menos de 5 habitantes por $\mathrm{km}^{2}$. La entidad de las cabeceras varía entre límites muy amplios debido a los desequilibrios en densidad y tamaño de las poblaciones de cada zona, con máximos residenciales y dotacionales en Cuéllar (la localidad tenía 9.483 habitantes en ese año) y mínimos en Navafría (374) y Sacramenia (484), oscilando los restantes entre los 1.287 resi-

14 Las valoraciones más altas hacían referencia al trato y la educación de los conductores (9,6 puntos), el confort de los vehículos $(8,5)$ y el tiempo de estancia en el destino $(8,4)$.

15 Director General de Transportes, Junta de Castilla y León (Federación Regional de Municipios y Provincias, julio 2012). 
dentes de Sepúlveda y los 3.532 de Cantalejo ${ }^{16}$. La elección de núcleos tan escasos en población como Navafría y Sacramenia se justifica por la aún menor entidad de los existentes en sus zonas de transporte, casi todos por debajo del umbral de los doscientos habitantes. Así, en la zona de Navafría solamente Pedraza superaba esa cifra (201) y además Navafría posee mayor accesibilidad gracias a la carretera N-110, mientras Sacramenia era -y sigue siendoel mayor núcleo de su zona, la menos poblada de Segovia, hallándose a escasa distancia de la carretera CL-603 -siguiendo la SG-242- que conduce a Aranda de Duero. La división EsteOeste de la provincia en cuanto al modelo de poblamiento queda patente en la representación cartográfica de los municipios menores de quinientos habitantes, localizados la mayoría de los existentes en el sector oriental, lo que convierte en cabeceras de ruta los núcleos más poblados de Cantalejo, Sepúlveda y Riaza. Las tres restantes cabeceras de ZTD del sector occidental, Cuéllar, Carbonero el Mayor y Nava de la Asunción se encuentran rodeadas por municipios más poblados, pero en una segunda aureola concéntrica también aparecen otros muchos con escaso número de residentes y faltos de servicios (Figura 6) ${ }^{17}$.

Figura 6

MAPA DE LOS MUNICIPIOS MENORES DE 500 HABITANTES EN LA PROVINCIA DE SEGOVIA (2013)

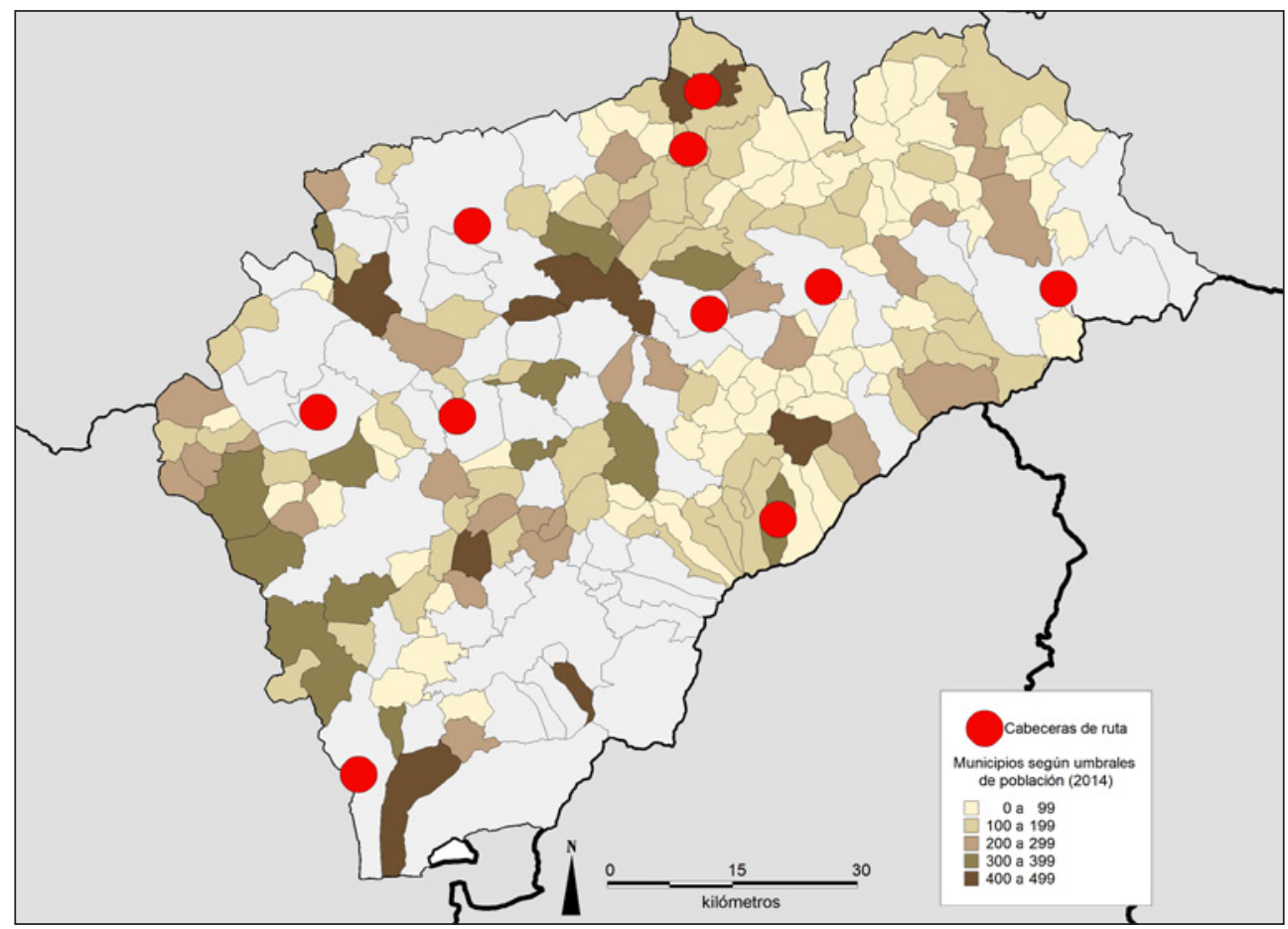

Fuente: elaboración propia a partir de INE: Padrón Municipal de Habitantes.

16 Todas las cifras de población corresponden al núcleo principal del municipio en el año de creación de su ZTD.

17 El mapa incluye además de las ocho cabeceras indicadas la de Villacastín, que estaba programada pero finalmente no se ha puesto en marcha debido a la falta de presupuesto para su mantenimiento. 
La lógica demográfica de la ubicación de las cabeceras de las ZTD es por tanto clara y acertada y a ella se añaden los restantes parámetros de especial relevancia ya enunciados. Los límites provinciales no constituyen una barrera obligada para su delimitación y pueden ser atravesados, de forma que las ZTD de una provincia proporcionan transporte a los núcleos de otras limítrofes. Sucede así en el sector más occidental, incluido en la ZTD abulense de Arévalo, que coincide asimismo con una Zona Básica de Salud, por lo que las poblaciones de esos municipios tienen a dicho núcleo como cabecera de ruta ${ }^{18}$. En sentido opuesto, la zona segoviana de Cuéllar dispone de rutas que sirven asimismo a varios núcleos vallisoletanos ${ }^{19}$. En muchas ocasiones los límites de las ZTD y las Zonas de Acción Social coinciden, casos de Cantalejo, Carbonero el Mayor, Cuéllar, Nava de la Asunción, Sepúlveda y Riaza, o lo hacen con los de una Zona Básica de Salud como sucede en Navafría y Sacramenia.

Siguiendo estas directrices el sistema de transporte a la demanda en la provincia de Segovia cubría a mediados de abril de 2014 ocho zonas de atención, con 61 rutas diferentes (Figura 7) que prestaban servicio a 272 núcleos de población, de los cuales 47 no contaban anteriormente con transporte público y en otros 43 no existían las conexiones establecidas por las nuevas rutas. La población con acceso al servicio sumaba en el conjunto de localidades beneficiadas 43.639 personas y desde sus inicios el servicio ha sido utilizado por 181.703 viajeros. Como puede comprobarse a través de los datos proporcionados por el Servicio de Planificación y Gestión de la Dirección General de Transportes de la Consejería de Fomento y Medio Ambiente las rutas de Cantalejo y Cuéllar son las más utilizadas, superando el centenar de viajeros semanales. En el extremo opuesto se encuentran la ZTD de Navafría, localizada en una de las comarcas con menor densidad de población, apenas una docena de localidades y menos de un millar de residentes si se exceptúa la cabecera.

Aunque la relación entre las cifras de población residente en cada ZTD y el número medio de viajeros semanales es lógica no siempre resulta directa y depende de otros factores. Por supuesto, la fecha de inauguración de las rutas condiciona el número total de viajeros hasta la actualidad, pero con poblaciones similares los desplazamientos varían pues las necesidades dependen de las características de cada población, el grado de utilización de vehículos particulares -inferior en las comarcas más envejecidas- y otros aspectos, como la cercanía y el tiempo de desplazamiento a la cabecera de cada zona o la presencia de servicios en otras localidades cercanas (Tabla 4). La ZTD de Cantalejo posee el mayor número e intensidad de tráfico semanal de pasajeros, 26 por cada mil habitantes, cuando el promedio provincial es de $11 \% o^{20}$. Su población es solo ligeramente inferior a la de la cercana ZTD de Cuéllar pero el poblamiento es más disperso y el equipamiento muy escaso fuera de la cabecera, siendo la adquisición de bienes de consumo uno de los motivos fundamentales de los desplazamientos. La situación con respecto a las variables indicadas es aún más extrema

18 Son los de Codorniz, Donhierro, Martín Muñoz de la Dehesa, Martín Muñoz de las Posadas, Montejo de Arévalo, Rapariegos y Tolocirio. Los límites provinciales se desbordan también en las ZTD colindantes con Burgos y Soria.

19 Bahabón, Campaspero, Camporredondo, Cogeces del Monte, Montemayor de Pililla, Santibáñez de Valcorba y Torrescárcela.

20 El índice se ha elaborado a partir del promedio de los datos semanales desde la puesta en marcha del servicio en cada una de las ZTD. 


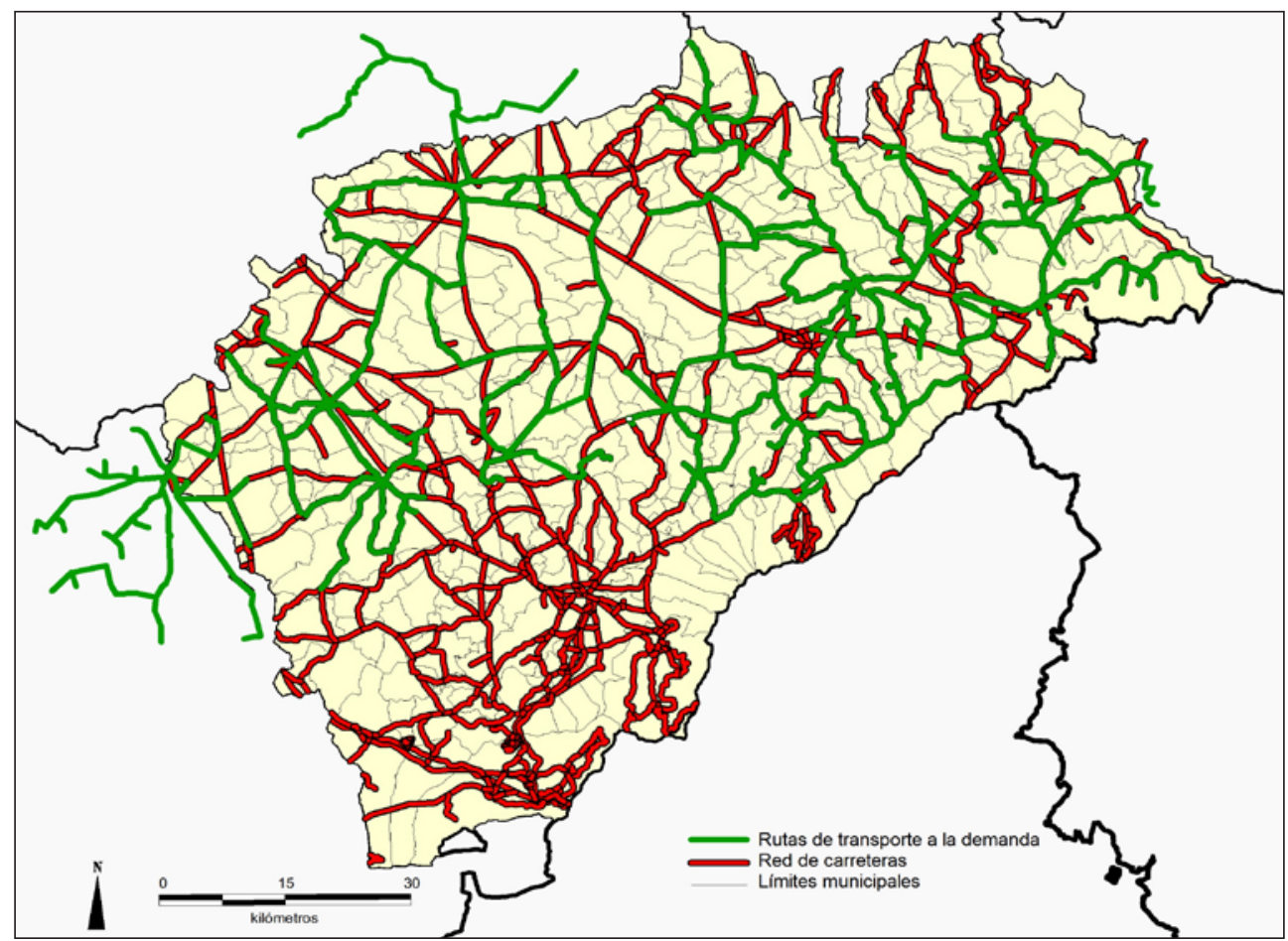

Fuente: Elaboración propia a partir de Junta de Castilla y León: Informe sobre evaluación del servicio de transporte a la demanda en relación con la accesibilidad de los servicios públicos esenciales en el medio rural de la Comunidad Autónoma a 29-02-2012.

en los núcleos pertenecientes a las zonas de Riaza (20\%o), Sepúlveda (17\%o) y Sacramenia (14\%o), si bien en ellas los índices son menores por la elevada edad media de sus habitantes, con porcentajes de octogenarios por encima del 20 e incluso $25 \%$.

El sistema no es cerrado y ya se ha visto cómo la Consejería de Fomento reorganiza desde 2012 los itinerarios para lograr una mejor adecuación de la oferta a la demanda de la población con menor capacidad de movilidad espacial, priorizando desplazamientos debidos a la necesidad -servicios públicos en general, abastecimiento, etc.- sobre los vinculados al ocio y manteniendo las zonas ya existentes. Los cambios afectaron al $43 \%$ de las expediciones -viajes-, modificando rutas, horarios y frecuencias, pero no son los únicos. La reestructuración de servicios ha modificado la frecuencia de los viajes semanales, consecuencia de la restricción del gasto derivada de la situación de crisis económica. En 2011 el total era de 312 viajes y en 2014 la cifra se había reducido a 200, aunque las localidades atendidas son las mismas. Tampoco han podido ponerse en funcionamiento las ZTD de Villacastín y de Segovia Rural, en el sector suroccidental de la provincia, ni la de Fuentesaúco en el septentrional. Villacastín y Fuentesaúco estaban en fase de diseño de rutas y 
Tabla 4

RUTAS DEL TRANSPORTE A LA DEMANDA EN LA PROVINCIA DE SEGOVIA. LOCALIDADES, POBLACIÓN, VEHÍCULOS Y VIAJES SEMANALES

\begin{tabular}{|l|r|r|r|r|r|r|r|r|r|}
\hline \multicolumn{1}{|c|}{ Zona } & $\begin{array}{c}\text { Fecha } \\
\text { de } \\
\text { inicio }\end{array}$ & $\begin{array}{c}\text { Semanas } \\
\text { en } \\
\text { servicio }\end{array}$ & $\begin{array}{l}\mathrm{N}^{\mathrm{o}} \text { de } \\
\text { rutas }\end{array}$ & $\begin{array}{c}\text { No de } \\
\text { núcleos de } \\
\text { población }\end{array}$ & $\begin{array}{c}\text { Población } \\
\text { total }\end{array}$ & $\begin{array}{c}\mathrm{N}^{\mathrm{o}} \text { de } \\
\text { viajeros }\end{array}$ & $\begin{array}{c}\text { Viajeros } \\
\text { por } \\
\text { semana }\end{array}$ & $\begin{array}{c}\mathrm{N}^{\circ} \text { de } \\
\text { vehículos }\end{array}$ & $\begin{array}{c}\text { Viajes } \\
\text { a la } \\
\text { semana }\end{array}$ \\
\hline Cantalejo & jun-06 & 403 & 8 & 28 & 4.507 & 46.527 & 115 & 1 & 31 \\
\hline $\begin{array}{l}\text { Carbonero el } \\
\text { Mayor }\end{array}$ & sep-05 & 442 & 5 & 19 & 7.100 & 28.967 & 66 & 2 & 20 \\
\hline Cuéllar & sep-05 & 442 & 8 & 36 & 13.857 & 47.933 & 108 & 2 & 24 \\
\hline $\begin{array}{l}\text { Nava de la } \\
\text { Asunción }\end{array}$ & abr-07 & 359 & 13 & 33 & 7.892 & 13.010 & 36 & 5 & 33 \\
\hline Navafría & may-08 & 302 & 5 & 41 & 3.012 & 6.309 & 21 & 2 & 10 \\
\hline Riaza & dic-07 & 327 & 9 & 50 & 3.377 & 21.561 & 66 & 6 & 38 \\
\hline Sacramenia & mar-10 & 210 & 4 & 12 & 975 & 2.792 & 13 & 1 & 8 \\
\hline Sepúlveda & sep-08 & 289 & 9 & 53 & 2.973 & 14.604 & 51 & 3 & 36 \\
\hline TOTAL & & & 61 & 272 & 43.693 & 181.703 & 476 & 22 & 200 \\
\hline
\end{tabular}

Fuente: Elaboración propia a partir de Junta de Castilla y León: Informe sobre evaluación del servicio de transporte a la demanda en relación con la accesibilidad de los servicios públicos esenciales en el medio rural de la Comunidad Autónoma a 29-02-2012 y Junta de Castilla y León: Balance del servicio de transporte a la demanda a 15-04-2014.

acuerdos con los operadores y las autoridades sanitarias pero la falta de presupuesto para su puesta en marcha y mantenimiento ha impedido por el momento seguir con el proyecto ${ }^{21}$.

La reducción de costes impuesta por las políticas aplicadas como respuesta a la crisis económica ha obligado nuevamente a buscar otras opciones complementarias para lograr la sostenibilidad del servicio. Una de ellas es la de compartir el transporte escolar con el de adultos, iniciativa conjunta de la Consejería de Fomento y Medio Ambiente y la de Educación, emulando experiencias precedentes ${ }^{22}$. El objetivo radica en poder atender las necesidades emanadas de la Ley de Ordenación, Servicios y Gobierno en el Territorio y a la vez mejorar y ampliar los servicios prestados mediante el transporte a la demanda, pero sobre todo en el ahorro derivado del aprovechamiento de las plazas libres existentes en los autobuses escolares. Propuesta en 2013, una de las tres experiencias piloto se puso en funcionamiento en la provincia en abril del mismo año, siguiendo el itinerario de transporte escolar de educación primaria entre La Mata de Rosueros, Carrascal, Berrocal, Aldeasaz, La Cuesta, Caballar y Turégano. Posteriormente el sistema se extendió a 21 rutas más en

21 Sección de Concesiones del Servicio de Planificación y Gestión de la Dirección General de Transportes (Consejería de Fomento y Medio Ambiente de la Junta de Castilla y León). La ZTD de Segovia Rural ni siquiera llegó a contar con una delimitación concreta.

22 La puesta en marcha en Galicia en 2002 (ARTS, 2003, p. 30) o en otras regiones europeas como Messara, Grecia (ARTS, 2003, p. 40). 
otras provincias de la Comunidad, y a lo largo del curso escolar 2013-14 lo hizo a una docena de rutas en Segovia, no sin despertar recelos y opiniones opuestas al mismo pese a respetar horarios y paradas. Por otra parte para el desarrollo de la citada Ley será preciso definir nuevas unidades básicas rurales -y urbanas-, solucionando los posibles conflictos de competencias entre administraciones públicas -Junta, Diputación y Ayuntamientosque el sistema de transporte a la demanda, centralizado y dependiente directamente de la Consejería de Fomento, ha evitado hasta el momento. Las incógnitas sobre el resultado de esta nueva iniciativa son por tanto numerosas, si bien las promesas sobre el mantenimiento de las ZTD actuales pronostican la coexistencia de estas rutas con otras de transporte mixto y líneas regulares en la nueva Ley de Ordenación del Transporte de Castilla y León, que define el transporte rural como «transporte interurbano de proximidad dirigido a satisfacer las necesidades básicas de movilidad de la población que reside en ámbitos rurales» y por la Ley de Ordenación del Territorio, delimitando el transporte de cercanías y estableciendo las conexiones con las cabeceras de servicios básicos y el acceso a rutas de medio y largo recorrido.

\section{CONCLUSIONES}

A comienzos del presente siglo existía en el medio rural de Castilla y León una demanda de transporte de viajeros insatisfecha derivada de la creciente concentración de los servicios en los centros comarcales. El envejecimiento demográfico y el elevado coste de las opciones disponibles disminuían la movilidad de la población, en especial en los núcleos de menor entidad, a la par que las líneas de transporte por carretera convencionales perdían usuarios como consecuencia de la despoblación. Esta problemática, cuya importancia quedó de manifiesto por las investigaciones realizadas en 2002 y 2004, dio origen a la implantación del transporte a la demanda, sustituyendo las líneas regulares de autobuses más deficitarias y creando nuevas rutas para permitir el acceso a los centros de servicios desde localidades hasta entonces carentes de transporte público.

Durante los primeros diez años desde el inicio de su puesta en funcionamiento el Servicio de Transporte a la Demanda ha demostrado ser una iniciática adecuada para facilitar la movilidad de la población en el medio rural, logrando un alto grado de satisfacción de sus usuarios. El diagnóstico realizado para la elección de las cabeceras de ruta y los itinerarios también se ha demostrado certero a la vista de los datos sobre su utilización. En 2014 los habitantes de 3.558 pequeñas localidades del medio rural accedían a servicios administrativos, comerciales, financieros, sanitarios y sociales ubicados en centros comarcales a los cuales anteriormente solo podían desplazarse mediante taxis, vehículos particulares o recurriendo a la ayuda de familiares y vecinos. Afirmaciones que se apoyan además en la concesión en 2011 a la Consejería de Fomento de la Junta de Castilla y León del Premio Nacional de la Asociación ITS España (Sistemas Inteligentes de Transporte) por la «mejor iniciativa en la aplicación de las nuevas tecnologías aplicadas al Transporte a la Demanda».

El modelo desarrollado en Castilla y León como respuesta a la problemática del transporte de viajeros en territorios aquejados por intensos procesos de despoblación no es sin embargo único, existiendo varios precedentes en la UE. Aun así, su avanzado desarrollo 
en un ámbito espacial tan extenso hace del mismo un ejemplo aplicable y exportable a otros países del entorno comunitario (Austria, Polonia, Portugal) ${ }^{23}$, como también a varias CC.AA. españolas ${ }^{24}$.

Junto a su valor social, en lo económico este sistema permite una menor inversión en ayudas para el sostenimiento del transporte rural de viajeros que las líneas regulares pues optimiza los recorridos en función de la demanda y minimiza por tanto los costes de explotación. Con todo, la reducción de gastos impuesta por las políticas de ahorro derivadas de la crisis económica no solo frenó la creación de nuevas zonas de transporte ya programadas y obligó a reorganizar rutas y disminuir la frecuencia de las expediciones, sino que impulsó la búsqueda de otras opciones alternativas. La nueva iniciativa encaminada a introducir sistemas de transporte mixto mediante la oferta de plazas vacías en el transporte escolar a la población adulta responde, sin duda, a este objetivo de ahorro, aplicando un modelo ya conocido en Europa. Es pronto para saber si estas modificaciones serán las adecuadas, pero por el momento la respuesta de los afectados no ha sido positiva. A la espera de una nueva consulta directa a usuarios, la realizada en 2012 indicaba el descenso del nivel de satisfacción a escala de la Comunidad y el muestreo realizado en Segovia en 2014 detectó insuficiencias en la mitad de las pequeñas localidades rurales. En conclusión, el transporte a la demanda, tras demostrarse necesario y exitoso, corre el riesgo de padecer los mismos problemas de otros servicios públicos como consecuencia de los recortes introducidos, cuando en realidad debería seguir compensando en lo posible, como hasta ahora ha venido haciendo, esas crecientes carencias.

\section{BIBLIOGRAFÍA}

ARTS (2003): Deliverable 3-Demonstrations Design and Implementation and Case Descriptions. Disponible en http://www.rural-transport.net/downloads/arts_d3.pdf (consultado 09-12-2014).

BACHILLER MARTÍNEZ, J.M. y MOLINA DE LA TORRE, I. (2014): «La localización de equipamientos y servicios en el medio rural: claves para la articulación territorial de Castilla y León». Ería, n ${ }^{\circ}$ 93, 77-100.

BRAKE, J., NELSON, J.D. and Wright, S. (2004): «Demand responsive transport: towards the emergence of a new market segment». Journal of Transport Geography, vol. 12, 323-337.

CABALLERO FERNÁNDEZ-RUFETE, P. y DELGADO URRECHO, J.M. (Dirs.) (2002): La situación de las personas mayores en Castilla y León. Valladolid. Consejo Económico y Social de Castilla y León.

23 Portugal puso en marcha la primeras ruta de transporte a la demanda en enero de 2013 y en mayo de 2014 abrió otras dos, las tres en la Comunidade Intermunicipal do Médio Tejo (Transporte a Pedido Médio Tejo).

24 Es el caso de Cantabria, donde se creó en 2004 un incipiente servicio de transporte a la demanda a raíz del Plan de Viajeros 2003-2007 en la comarca del Alto Asón con cabecera en Ramales de la Victoria, dando servicio a una población en torno a los diez mil habitantes (Lois y Pazos, 2005); sin embargo no será hasta 2014 cuando, en el Proyecto de Ley de Transporte de Viajeros por Carretera, se incluya el transporte a la demanda como tal (Proyecto de Ley de Transporte de Viajeros por Carretera, Capítulo 4, Subsección 1 ${ }^{\mathrm{a}}$ : Disposiciones particulares sobre determinados tipos de transporte, en Boletín Oficial del Parlamento de Cantabria de 17 de julio de 2014, p. 17.539). En Galicia se incluirá en la próxima Ley de transporte público, según anuncio de Xunta. 
DE LAS RIVAS SANZ, J.L. (2010): «Necesidades de transporte en el medio rural de Castilla y León: condicionantes territoriales». I Foro internacional de transporte rural: Transporte a la demanda. Valladolid, 21 de abril de 2010.

DELGADO URRECHO, J.M. y CABALLERO FERNÁNDEZ-RUFETE, P. (Dirs.) (2005): La situación de los nuevos yacimientos de empleo en Castilla y León. Valladolid. Consejo Económico y Social de Castilla y León.

FARRINGTON, J. y FARRINGTON, C. (2005): «Rural accessibility, social inclusion and social justice: towards conceptualization». Journal of Transport Geography, vol. $13,1-12$.

FUNDACIÓN ENCUENTRO (2012): Informe España 2012. Una interpretación de su realidad social. Madrid. Fundación Encuentro.

FUNDETEC (2008): Libro Blanco de las TIC en el Sector Transporte y Logística. Valladolid. Junta de Castilla y León.

HOLMGREN, J. (2013): «The efficiency of public transport operations. An evaluation using stochastic frontier analysis». Research in Transportation Economics, vol. 39, 50-57.

JUNTA DE CASTILLA Y LEÓN (2004): Información general sobre el Centro Virtual de Transporte Público a la Demanda. Valladolid. Consejería de Fomento y Medio Ambiente.

JUNTA DE CASTILLA Y LEÓN (2008): Estrategia Regional de Desarrollo Sostenible 2009-2014. Valladolid. Consejería de Fomento y Medio Ambiente.

LAWS, ENOCH, ISON y POTTER (2009): «Demand responsive transport: a review of schemes in England and Wales». Journal of Public Transportation, vol. 12 (1), 19-37.

LOIS GONZÁLEZ, R.C. y PAZOS OTÓN, M. (2005): «Nuevas perspectivas para la movilidad en los espacios rurales: experiencias y posibilidades para la montaña cantábrica» en La montaña cantábrica. Una montaña viva (Delgado Viñas C., ed.). Santander, Edit. Universidad de Cantabria y Parlamento de Cantabria, 117-128.

MARTÍNEZ FERNÁNDEZ, L.C. y LUENGO GALLEGO, J.A. (2004): «Concentración y difusión de la actividad industrial en Castilla y León. El papel de las infraestructuras de transporte en las dinámicas territoriales». Revista de Economía y Finanzas de Castilla y León, $\mathrm{n}^{\circ}$ 9, 51-76.

MARTÍNEZ FERNÁNDEZ, L.C. y DELGADO URRECHO, J.M. (2013): «Población, administración y territorio en Castilla y León: desequilibrios y desafíos del modelo de poblamiento». Ería, no 90, 5-30.

MARTÍNEZ FERNÁNDEZ, L.C. y MORENO MÍNGUEZ, A. (Eds.) (2014): La provincia de Segovia. Interpretación del espacio y definición del modelo territorial. Segovia. Diputación Provincial de Segovia.

NOGUERA TUR, J. y FERRANDIS MARTÍNEZ, A. (2014): «Accesibilidad y provisión de servicios de interés general en las áreas rurales de la Unión Europea: un análisis a partir del Eurobarómetro». Boletín de la Asociación de Geógrafos Españoles, n 64, 377-404.

OÑA LÓPEZ, J. (2010): «Una revisión de más de 50 experiencias de transporte a la demanda en Europa». I Foro Internacional de Transporte Rural: Transporte a la demanda. Valladolid, 21 de Abril de 2010.

SMITH, N., HIRSCH, D. y DAVIS, A. (2012): «Accessibility and capability: the minimum transport needs and costs of rural households». Journal of Transport Geography, vol. 21, 93-101. 
SUÁREZ RICO, T. (2004): «Una experiencia de creación de recursos para personas mayores en un área rural dispersa de Asturias: Programa Rompiendo Distancias de Taramundi» en ¿Qué futuro para los espacios rurales? (VV.AA.). León, Edit. Grupo de Trabajo de Geografía Rural de la AGE y Secretariado de Publicaciones de la Universidad de León, 677-687.

SCHWANEN, LUCAS, CARRASCO, NEUTENS, AYELKIN y CISTERNAS (2013): «Reconceptualising the links between transport disadvantage and social exclusion». UTSG, 45th Annual conference, Proceedings. Oxford, Enero de 2013. 